Solid Earth Discuss., https://doi.org/10.5194/se-2017-52

Manuscript under review for journal Solid Earth

Discussion started: 13 June 2017

(c) Author(s) 2017. CC BY 3.0 License.

\title{
1 Imaging and quantification of the 2 pore microstructure of gas shales using X-ray microtomography
}

\author{
Mozhdeh Mehrabi ${ }^{1}$, Mehrdad Pasha ${ }^{1}$, Ali Hassanpour ${ }^{1}$, Paul W.J. Glover ${ }^{2}$ \& \\ Xiaodong $\mathrm{Jia}^{1}$ \\ ${ }^{1}$ Institue of Particle Science and Engineering, School of Chemical and Process Engineering, \\ University of Leeds, Leeds, LS2 9 JT, UK \\ ${ }^{2}$ School of Earth and Environment, University of Leeds, Leeds, LS2 9JT, UK \\ ${ }^{*}$ Corresponding author email, A.Hassanpour@leeds.ac.uk
}

Abstract

Optimisation of gas production from shale gas reservoirs depends critically upon a good understanding of the porosity and pore microstructure of the shale. Conventionally surface area measurements or mercury porosimetry have been used to measure the porosity in gas shales. However, these conventional methods have limited accuracy and only provide a bulk measurement for the samples. More recently, scanning electron micrography (SEM) and Focussed Ion Beam SEM (FIB-SEM) techniques have been applied in an attempt to address these limitations. Unfortunately, these two methods destroy the samples. In this research three-dimensional x-ray micro tomography (XRMT) imaging techniques were used to capture the structure of three samples and also compared to data from mercury porisimetry. The resulting data have been segmented in order to recognize individual pores down to a resolution of about $1 \mu \mathrm{m}$. Distributions of pore volume, pore size, pore aspect ratio, surface area to pore volume ratios and pore orientations were calculated from the XRMT data. It was found that the porosity obtained from XRMT measurements is smaller than that obtained using mercury porisimetry, the reason for which might be displacement of kerogen by the high pressures generated in the mercury technique, but is unlikely to be due to both techniques not being able to measure pores smaller that about $900 \mathrm{~nm}$. Pore volume and size distributions showed all of the shales tested in this work to be multimodal with similar major modal values for volume and pore size. The pores also have a range of pore aspect ratios and surface area to pore volumes, including values indicating the presence of significant oblate spheroidal pores where the major axis is up to 330 times bigger than the minor axis. This has implications both for the connectedness of pores and the resultant gas permeability and the effectiveness of gas desorption processes into the gas shale's pores. These high aspect ratio pores were oriented both in dip and azimuth in preferential directions making it likely that the shale gas itself has significant anisotropy both for permeability and in its mechanical properties. Permeabilities calculated from the XRMT distribution data matched very well with permeabilities obtained by scaling considerations and typical values for similar gas shales.
\end{abstract}

Keywords. Gas shales, XRMT, anisotropy, porosity, permeability, heterogeneity, mercury porosimetry. 
Solid Earth Discuss., https://doi.org/10.5194/se-2017-52

Manuscript under review for journal Solid Earth

Discussion started: 13 June 2017

(c) Author(s) 2017. CC BY 3.0 License.

\section{Introduction}

Recently research into extracting unconventional resources has increased as oil and gas production from conventional reservoirs continues to decline. Within fifty years it is expected that all hydrocarbon reservoirs will either be small, low permeability, heterogeneous, anisotropic, found in difficult to reach locations, or some combination of these (Miller et al., 2014). Consequently, unconventional reservoirs are becoming an important alternative source of natural gas to meet the huge global demand for energy (Alfred and Vernik, 2012).

According to IHS Markit (Edwards, 2015), unconventional reservoirs already account for about two thirds of current global reserves. However, the extraction of hydrocarbons from these extremely low porosity and permeability rocks is extremely difficult. Not only do we not know how much of it we might be able to extract, its extraction requires the use of new techniques and special recovery operations whose cost makes producing these reservoirs often marginally economic and less hydrocarbon prices rise.

Unconventional hydrocarbon resources exist in a number of different forms including tight gas and oil reservoirs, coal bed methane deposits and thick formations containing shale gas. This paper focuses on significant shale gas deposits. It recognises that the gas held in shale gas deposits occupies a pore microstructure of which little is known, at least at a microscopic scale. Since it is these rocks that need to be hydraulically fractured so that gas will flow from them, we consider that a better understanding of the microstructure of gas shales will be extremely useful in designing ways to extract more shale gas from them. According to the United States Energy Information Administration (USEIA), 60\% of the Earth's sedimentary crust consists of shale, and the organic matter in it is the primary source of all hydrocarbons, as either a gas or oil (Blyth and De Freitas, 1984). Shale is a fine grain sedimentary rock derived from clastic sources and which contains a significant amount of different clays mixed with fragments of quartz and other minerals. The organic material that is deposited with these mineral particles (clasts) is altered by temperature and pressure (Tissot and Welte, 1978) leading to the formation of kerogen and the creation of maturation-induced pore space filled with hydrocarbons. However, these hydrocarbons remain trapped within the shale because of the rock's ultra-low permeability (Alfred and Vernik, 2012). The increased pore pressure created through hydrocarbon generation could also result in maturation-induced micro-cracks (Vernik and Liu, 1997) that may provide increased migration of hydrocarbon into reservoirs, creating the world's conventional oil and gas resources. However, much of the hydrocarbons, remain in the shale source rocks because they occupy and cannot leave a rock microstructure consisting of millions of extremely small and often unconnected pores (Alfred and Vernik, 2013). During production, access to this trapped gas is currently improved by the use of hydraulic fracturing. However, this process is presently a very much hit and miss affair because we do not know how the shale gas is distributed within the gas shale at a microscopic to macroscopic scale (Richardson et al., 2013) and we have limited ability to control and focus the growth of fractures.

Improvements to hydraulic fracturing design and proppant technology have already led to a step change in shale gas production rates. Significant improvements have been shown to occur when the hydraulic fracturing takes full account of the mechanical properties of the rocks (Glover et al., 2000), while high aspect ratio fibre and channelized proppant technology (Schlumberger, 2015) has produced up to $20 \%$ greater production rates. Further increases in production rates are likely to be possible by designing hydraulic fracturing campaigns that take account of the microscopic distribution of the hydrocarbons within the shale, but for this to be done we also need more information about how the hydrocarbons are distributed within the shale at a microstructural level (Gerke et al., 2013).

Up until now, most studies of the pore structure of shale have used mercury injection capillary pressure (MICP) and nuclear magnetic resonance (NMR) measurements 
Solid Earth Discuss., https://doi.org/10.5194/se-2017-52

Manuscript under review for journal Solid Earth

Discussion started: 13 June 2017

(c) Author(s) 2017. CC BY 3.0 License.

(Sondergeld et al., 2010). The mercury technique, though extremely useful in conventional reservoirs, is less relevant in shales since the injection pressures need to be extremely high to mercury penetrate into the rock at all. These higher pressures begin to compress the rock, crushing the pore spaces that the technique is supposed to be probing, and leading to overestimation of capillary pressures together with underestimations of pore size, pore throat size and porosity. Additionally, neither of these techniques provides information about the microstructure of the pores and how they are connected. On the other hand the NMR technique provides some information about the microstructure but suffers from low resolution and cannot measure the connectivity of the pores.

Consequently, another approach is needed. The microstructure of shale has been imaged extensively using Focused Ion Beam (FIB) SEM techniques (Chalmers et al., 2012; Loucks et al., 2009; Ambrose et al., 2010; Passey et al., 2010; Schieber, 2010; Sondergeld et al., 2010). However, use of the FIB-SEM method to characterize the 3D microstructure of rock is destructive and very time consuming. A better alternative for quantifying pore structure would be to use 3D X-ray tomography because it is non-destructive, fast, and allows the same sample to be scanned repeatedly. Other allied technologies such as NMR scanning (Sondergeld et al., 2010) and Positron Emission Tomography (Ogilvie et al., 2001) suffer from the same low resolution (approximately $1 \mathrm{~mm}$ ). We are beginning, however, to see the use of X-ray micro-tomography (XRMT) (Iglauer et al., 2013; Panahi et al., 2014; Reipe et al., 2011; Mayo et al., 2015; Peng et al., 2012; 2015) using highly focused X-Ray beams in the laboratory, which can attain resolutions better than 1 micron. Standard X-ray micro-tomography apparatus can attain resolutions down to $760 \mathrm{~nm}$ in ideal conditions, which is sufficient to image most pores in shale, while some apparatus can provide resolutions as low as $20 \mathrm{~nm}$.

This work describes an X-ray micro-tomography study to image the microstructure of samples of gas shale at a micron-scale in order to characterise the pore structure. Information has been gathered on microstructural parameters such as the location, size, volume, shape, surface area to volume ratio and preferred orientations of pores in order to help understand how the rock was formed, how it acts as a reservoir for gas, how we can improve gas permeability in such rocks, and how, ultimately, we can extract more gas in an efficient manner. We believe that the characterization of gas shale pore structure must lead to improvements in the amount of gas we can extract from a given reservoir.

$\mathrm{X}$-ray microtomography like other techniques has some limitations (Blunt et al., 2013), including resolution limits, a trade-off between resolution and sample size, and difficulties in segmentation for materials (or phases) with similar densities due to similar Xray absorption coefficients. However, these limits are more than made up for by the advantage is the technique has over other imaging techniques when it comes to the imaging of gas shales.

In this work we have recognized that before characterisation of gas shales requires an even higher resolution than the $900 \mathrm{~nm}$ resolution reported here, and we are currently carrying out further imaging with a much better resolution (down to $50 \mathrm{~nm}$ ), which will be the subject of further publication.

\section{Methodology}

\subsection{Samples}

The samples imaged in this work have a European source, but due to a confidentiality agreement, it is not possible to disclose further details. Associated mercury injection capillary pressure (MICP) measurements have indicated that the porosity varies between $2.8 \%$ and $10.4 \%$, while $\mathrm{X}$-ray diffraction (XRD) measurements have shown that the samples 
Solid Earth Discuss., https://doi.org/10.5194/se-2017-52

Manuscript under review for journal Solid Earth

Discussion started: 13 June 2017

(c) Author(s) 2017. CC BY 3.0 License.

are composed of 49.2 and 58.3 wt.\% clays, 24.2 to 29.4 wt.\% quartz and feldspars, 3.7to 16.1 wt.\% carbonates and 2.5 to 8.9 wt.\% kerogen (Table 1 ).

\subsection{Sample preparation}

In order to optimise the scanning resolution, the sample should be as small as possible and the X-ray source should be brought close to the rotating sample.

In this work samples were prepared by taking a small core of shale and cutting it into 2 pieces of about $2 \times 1 \mathrm{~cm}$ each. Each piece was then mounted on a glass slide $(48 \times 26 \mathrm{~mm})$ using thermoplastic wax. In order that the data from different samples can be compared our preparation protocol demands samples are cut into approximately the same size. Each face of the mounted sample was first machined to $1 \mathrm{~mm}$ thick using a Buehler PetroThin instrument, turning the sample over and remounting it on the glass slide until a cube of side $1 \mathrm{~mm}$ was all that remained. Once complete a similar process was carried out on other faces to reduce the sample to a cube of about $500 \mu \mathrm{m}$ in all dimensions. The thickness of wax between the glass slide and the surface of the sample has been estimated to be $15-20 \mu \mathrm{m}$, leading to the corresponding uncertainty in sample size. The samples were finally cleaned with acetone and mounted at the top of a rotating sample holder with cyanoacrylate epoxy.

\subsection{X-ray Microtomography}

$\mathrm{X}$-ray micro tomography (XMT) is a non-destructive, relatively fast and accurate technique, which can reveal the internal structure of the shale samples. The technique can be used to scan the sample as many times as needed to visualize internal properties and build a 3D internal structure of the samples (Bakke and Oren, 1997; Li et al., 20010; Curtis et al., 2010; Gelb et al., 2011).

The process of X-ray computed tomography (XRMT) consists of taking a number of $\mathrm{X}$-ray radiographs (referred to as projection images) at various angles by projecting an X-ray beam through the specimen and measuring the attenuation of the beam received on a detector (Markowicz, 1993), as shown in Figure 1. Attenuation is quantified in terms of a CT number, with a larger CT numbers being associated with materials have a higher atomic number and density. The projection images are obtained at a large number of different angles as the sample rotates. A technique known as Filter Back-projection (Mersereau and Dudgeon, 1975) can then be used to reconstruct the 3D volume of the specimen.

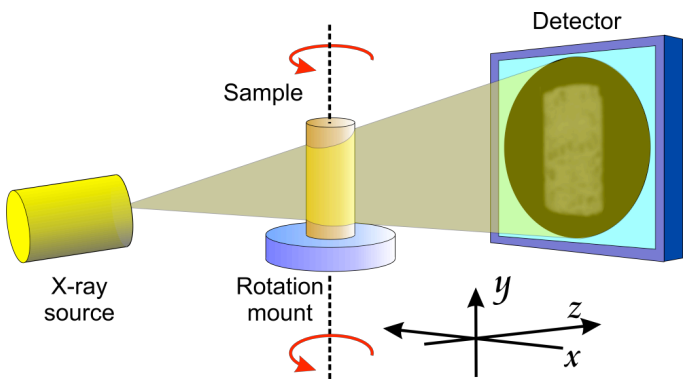

Figure 1. Schematic representation of a computerised micro-tomography measurement set-up.

X-ray Microtomography (XRMT) has enough sensitivity to distinguish gas-filled pores from solid kerogen primarily due the large difference in their densities, which leads to a contrast in their CT numbers. In our research the contrast between kerogen and gas-filled pores has been enhanced by adjusting the X-Ray power (i.e., the voltage and current). A simple method for checking whether a pore of crack is gas-filled is to compare the grey-level 
Solid Earth Discuss., https://doi.org/10.5194/se-2017-52

Manuscript under review for journal Solid Earth

Discussion started: 13 June 2017

(c) Author(s) 2017. CC BY 3.0 License.

of the pore or crack with voxels outside the sample. Kerogen mapping will be the subject of a future publication.

Once the 3D volume of the specimen has been obtained, a series of image analysis techniques can be used to visualise the internal structure of the specimen and obtain digital information on its 3D geometry and structural properties.

In this study a GE Phoenix Nanotom (XRMT) instrument at the Institute of Particle Science and Engineering at the University of Leeds has been used to obtain the 3D volume of the samples. This apparatus has a microfocus $\mathrm{X}$-ray generator and narrow beam, which allows for the examination of high-density materials such as rocks. The final resolution is determined by the sample size, beam quality and the detector specifications as well as the position of the rotating sample with respect to the beam and the detector. For the samples studied in this research the voxel resolutions of the images were $1.2 \mu \mathrm{m}$ for Sample 1, 0.9 $\mu \mathrm{m}$ for Sample 2, and $1.0 \mu \mathrm{m}$ for Sample 3.

VGStudio software was used to reconstruct the images from projection images and Avizo Fire software was used for image analysis on the obtained volumes. The image analysis provided sample porosity, pore volume, pore aspect ratio, the ratio of the pore surface area to pore volume, the distribution of pore throat sizes, the connectivity of the pores and any preferential directionality (anisotropy) in the pore distribution.

\subsection{D SEM Scoping Study}

To complement this study, samples were also investigated using a scanning electron microscope (SEM) and associated energy dispersive spectroscopy (EDS) imaging. The data acquired in these experiments, allowed identification of the type of minerals and the presence of pre-existing cracks. For example, bright spots in images, often composed of clusters of crystals, as shown in all three panels of Figure 2 indicate pyrite framboids, while fractures are visible clearly.

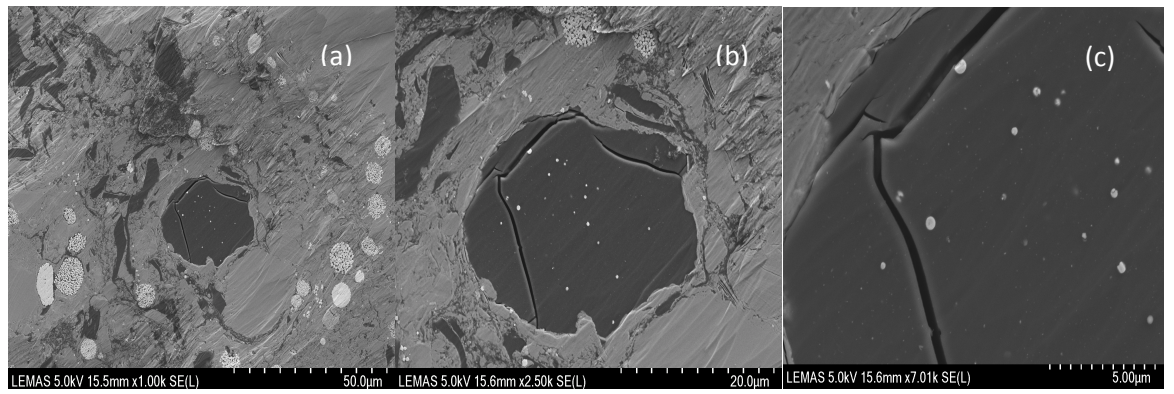

Figure 2. SEM image of Sample 2 at (a) $50 \mu \mathrm{m}$, (b) $20 \mu \mathrm{m}$ and (c) $5 \mu \mathrm{m}$ resolutions. The lightest areas correspond to dense material with high atomic number such as pyrite, the darker areas represent low density, and low atomic number components such as organic materials, and the darkest regions indicate pores and cracks.

\section{Results and Discussion}

\subsection{Numerical analysis of scan data}

Figure 3 shows the reconstructed and filtered three-dimensional images from Sample 1. Figure 3(a) shows clearly the complex nature of the microstructure of the shale. There are connected and unconnected pores at all scales and of all aspect ratios as well as pre-existing fractures, again at all scales, some of which may have been the result of sample preparation. In addition there is a complex mixture of minerals including high-density pyrite, which has a high CT number, and shows up at small white small aspect ratio spots.

The pores were segmented using a defined range of grey values corresponding to gas-filled pores by using manual thresholding, as shown in Figure 3 (b). It is worthwhile 
Solid Earth Discuss., https://doi.org/10.5194/se-2017-52

Manuscript under review for journal Solid Earth

noting that most of the pore space is not well-represented in this figure due to the resolution of the figure rather than the resolution of the data.

Figure 3(c) and (d) show the three-dimensional pore structures of Sample 1, the pores have been colour coded according to whether contiguous voxels are part of the same pore. In this way each colour represents a fully connected pore. (It should be noted that two clearly separate patches that have the same colour are not connected, but share the same colour simply because of cycling over a limited number of colours in the available palette.)

It is possible to analyze the size and spatial distribution of the pore space as well as its connectedness.
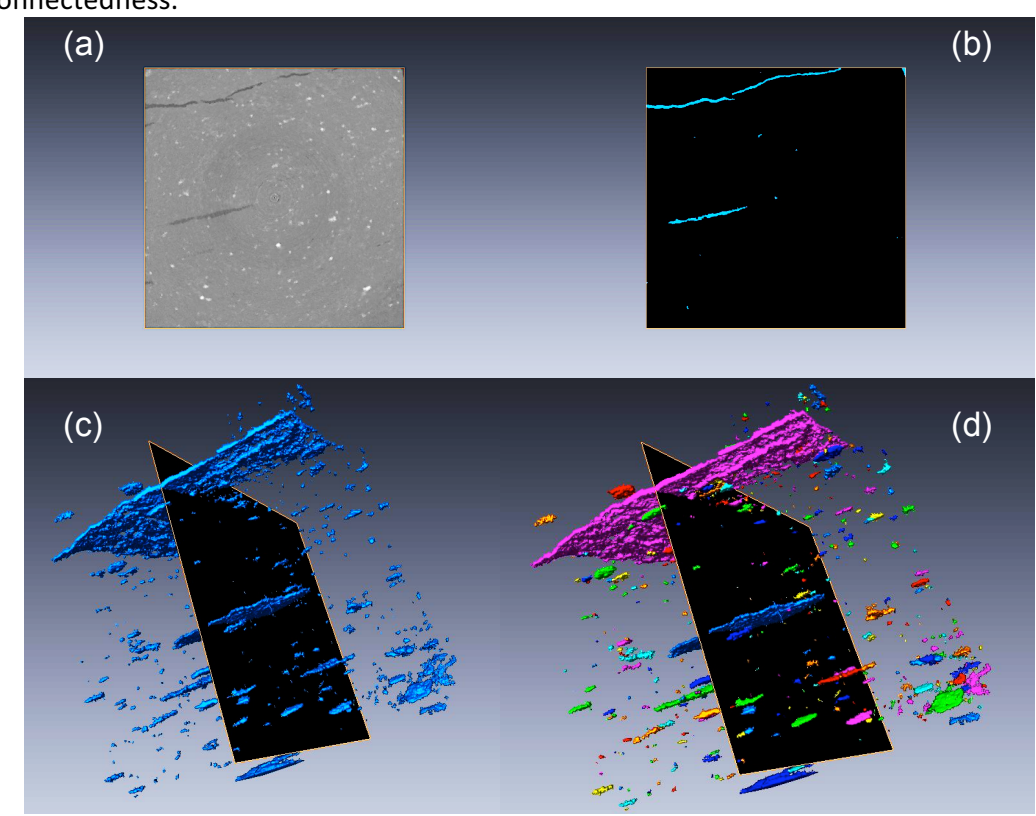

Figure 3. Image processing workflow, (a) 2D slice of a $0.5 \times 0.5 \times 0.5 \mathrm{~mm}$ volume of Sample 1 using a non-loca mean filter, (b) the segmented of pore spaces obtained by thresholding with specific range of CT numbers (represented by grey-levels) corresponding to pores, (c) 3D volume of pores for the Sample 1, (d) 3D image of the connected pores, as the cluster of connected pores are shown in same colour.

Table 1 shows a selection of the most important data from the analysis of the three samples. The most obvious conclusion from the data in Table 1 is that the porosity derived from X-ray micro-tomography is significantly (between 1.5 and 10 times) less than that provided by MICP measurements. This discrepancyis difficult to explain by experimental inaccuracies, and leads to questions over whether use of either the porosity from the MICP technique or the porosity calculated from the micro-tomography is correct in gas shale. One possible cause of the discrepancy is that the fact that the MICP measurement is overestimated due to the high pressures damaging the sample. However, one would expect this to reduce the measured porosity rather than increasing it. Another explanation might be that XRMT at the resolutions available to us are not taking into account pores smaller than our resolution limit (about $900 \mathrm{~nm}$ ), which would imply that nanopores are extremely important in gas shales. However, these small pores should also be missed by the MICP measurement. Alfred and Vernik $(2012 ; 2013)$ have recently published a new petrophysical model for gas shales, distinguishing between open porosity and kerogen-filled porosity. Consequently, another source of the apparent discrepancy between the two porosities would arise if the high pressures used in the MICP technique have disturbed the kerogen in the rock samples. This would lead to the MICP measurement returning a porosity composed of the initial gas-filled porosity and some of the space previously occupied by kerogen, 
Solid Earth Discuss., https://doi.org/10.5194/se-2017-52

Manuscript under review for journal Solid Earth

Discussion started: 13 June 2017

(c) Author(s) 2017. CC BY 3.0 License. that the density of kerogen in the Marcellus shale varies with thermal maturity in the range 1.53 to $1.79 \mathrm{~g} / \mathrm{cm}^{3}$. If we take a mean density of $1.65 \mathrm{~g} / \mathrm{cm}^{3}$ for kerogen and $2.7 \mathrm{~g} / \mathrm{cm}^{3}$ for the other solid components of the rock, we obtain kerogen values of $3.93 \%$ by volume for Sample 1 and 3 and $12.56 \%$ for Sample 2. Clearly, there is ample scope for the process proposed by Alfred and Vernik to occur. If such a process does occur, it would be extremely important to know what technique was used to measure the porosity of gas shale from a hydrocarbon potential point of view. Furthermore, comparison of porosity measurements using two different techniques would possibly allow the fraction of kerogen in the rock to be determined.

\begin{tabular}{|c|c|c|c|c|}
\hline Parameter & Unit & Sample 1 & Sample 2 & Sample 3 \\
\hline \multicolumn{5}{|l|}{ Composition } \\
\hline Clays & & 49.2 & 58.3 & 49.2 \\
\hline Quartz \& feldspar & w.t\% & 29.4 & 24.2 & 29.4 \\
\hline Carbonate & & 16.1 & 3.7 & 16.1 \\
\hline Kerogen & & 2.5 & 8.9 & 2.5 \\
\hline Porosity from MIP & $(-)$ & 0.104 & 0.028 & 0.104 \\
\hline Pore voxels count & $(-)$ & 633 & 100 & 258 \\
\hline Total voxel count & $(-)$ & $10^{9}$ & $10^{9}$ & $10^{9}$ \\
\hline Spatial resolution (voxel size) & $(\mu \mathrm{m})$ & 1.2 & 0.9 & 1.0 \\
\hline Voxel volume & $\left(\mu m^{3}\right)$ & 1.73 & 0.73 & 0.82 \\
\hline Porosity from microtomography & $(-)$ & 0.0071 & 0.0029 & 0.0096 \\
\hline Volume of smallest pore & $\left(\mu \mathrm{m}^{3}\right)$ & 13.8 & 2.19 & 4.6 \\
\hline Volume of largest pore & $\left(\mu m^{3}\right)$ & $5.97 \times 10^{6}$ & $9.96 \times 10^{4}$ & $2.47 \times 10^{5}$ \\
\hline Mean pore volume & $\left(\mu \mathrm{m}^{3}\right)$ & $1.85 \times 10^{4}$ & $7.32 \times 10^{3}$ & $3.19 \times 10^{3}$ \\
\hline Median pore volume & $\left(\mu \mathrm{m}^{3}\right)$ & $6.15 \times 10^{2}$ & $1.32 \times 10^{3}$ & $7.28 \times 10^{2}$ \\
\hline Effective pore radius & $(\mu \mathrm{m})$ & 1.43 & 1.33 & 1.42 \\
\hline Formation factor & $(-)$ & $2.8 \times 10^{6}$ & $41 \times 10^{6}$ & $1.13 \times 10^{6}$ \\
\hline Estimated permeability & $(n D)$ & 92.3 & 5.5 & 22.3 \\
\hline
\end{tabular}

\subsection{Pore size and pore volume distributions}

The pore volume distribution for each sample is shown in Figure 4 and can be seen to cover an extremely wide range, from the resolution of the technique in Sample $2(900 \mathrm{~nm})$ to about five orders of magnitude higher. Figure 4 shows both the incremental and cumulative distribution of pore volumes for each of the three samples. It can be seen that pore volumes range from below $2 \times 10^{-9} \mathrm{~mm}^{3}$ to over $2 \times 10^{-4} \mathrm{~mm}^{3}$. For these three samples all pore volume distributions are multimodal but the largest contribution to pore volume in all three samples occurs at a pore volume of about $1.5 \times 10^{-6} \mathrm{~mm}^{3}$, accounting for about $18 \%$ of the total pore volume for Sample 1, 21\% for Sample 2 and $41 \%$ for Sample 3 by pore number count.

The lower limit of the distribution measured in this work is controlled by the resolution of the technique, with samples 1 and 3 showing a marked reduction in measured pores with volumes less than $1.5 \times 10^{-8} \mathrm{~mm}^{3}$, and $2.5 \times 10^{-9} \mathrm{~mm}^{3}$ for Sample 2 . The multimodal character of the distributions hints that there may be significant pore volume in the form of pores with sizes less than the resolution of the XRMT technique.

The upper limit to pore sizes in Sample 2 and Sample 3 is about $1.5 \times 10^{-4} \mathrm{~mm}^{3}$ and $2.5 \times 10^{-4} \mathrm{~mm}^{3}$, respectively, while for Sample 1, with the presence of a one large crack, it is $6 \times 10^{-3} \mathrm{~mm}^{3}$. 
Solid Earth Discuss., https://doi.org/10.5194/se-2017-52

Manuscript under review for journal Solid Earth

Discussion started: 13 June 2017

(c) Author(s) 2017. CC BY 3.0 License. consistently higher pore volumes than Sample 2 despite the similarity apparent in their associated incremental pore volume distributions.

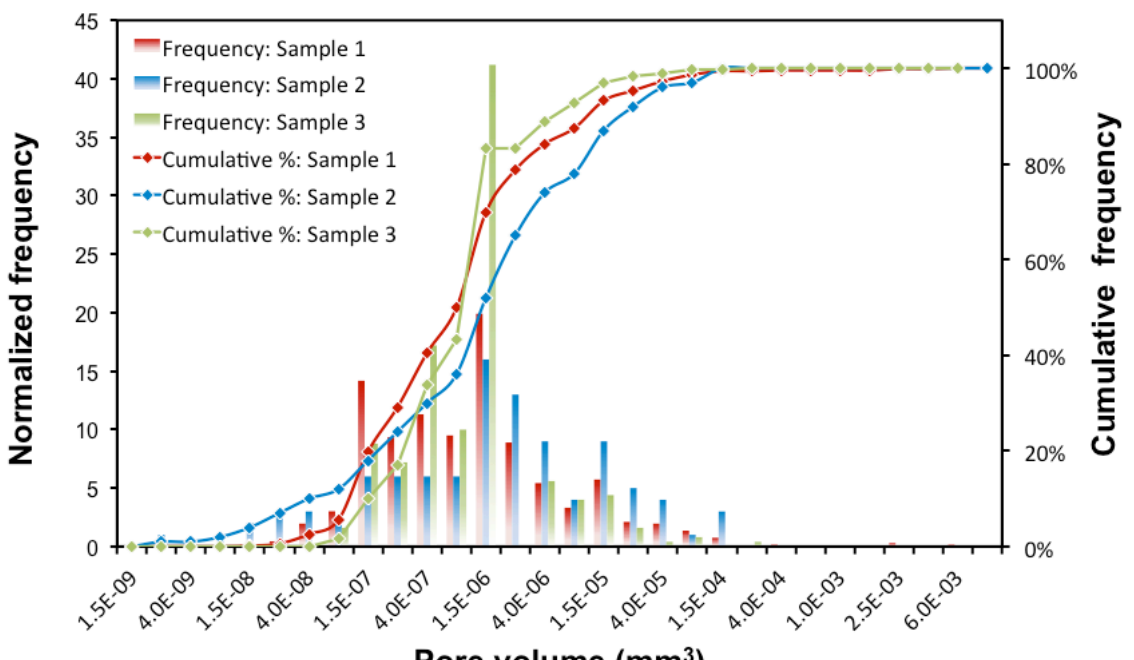

Pore volume $\left(\mathrm{mm}^{3}\right)$

Figure 4. Incremental and cumulative pore volume distribution for Sample 1 (Red), Sample 2 (Blue) and Sample 3 (Green).

\subsection{Pore aspect ratios}

Pores can be considered to approximate to an ellipsoid with radii $a, b$ and $c$ in each of the three orthogonal directions $x_{1}, y_{1}$ and $z_{1}$, where $x_{1}$ is taken along the maximum length of the ellipsoid, $y_{1}$ along the next largest, and $z_{1}$ along the smallest ellipsoidal dimension. Aspect ratios can then be described as the ratio of pairs of each of these orthogonal lengths. In this work we calculate the aspect ratio of two largest bounding box dimension of pores, which is given by the ratio $a / b$, where $a \geq b \geq c$. Feret's diameter (Merkus, 2009) was used to calculate the values of $a$ and $b$ for each pore from the numerical data set. 
Solid Earth Discuss., https://doi.org/10.5194/se-2017-52

Manuscript under review for journal Solid Earth

Discussion started: 13 June 2017

(c) Author(s) 2017. CC BY 3.0 License.

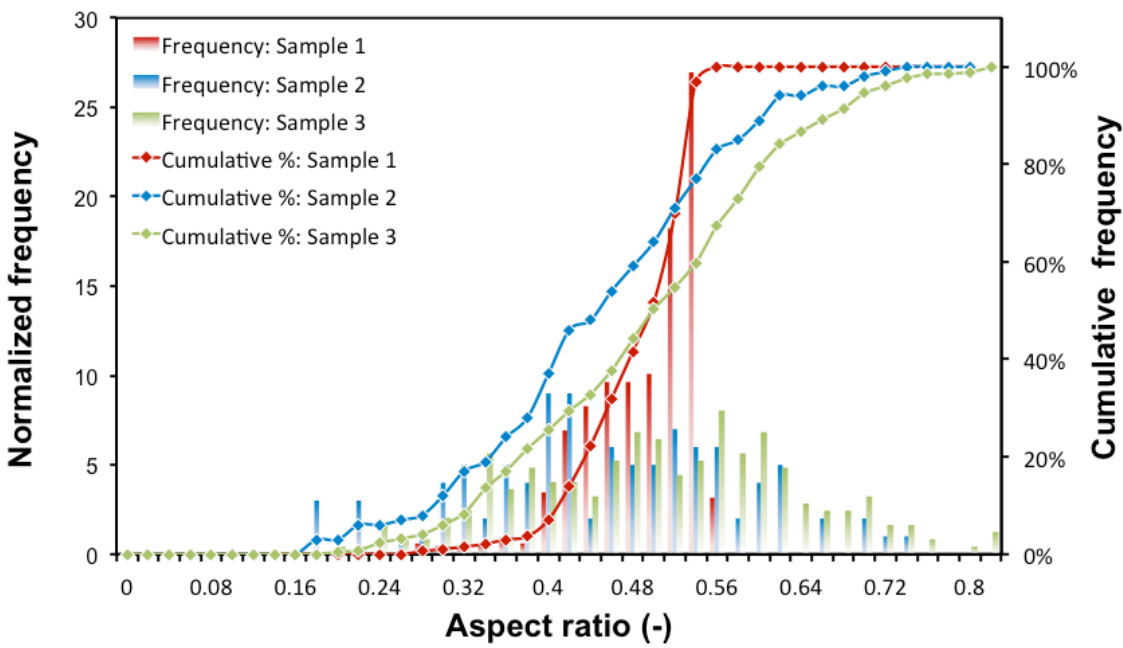

Figure 5. Aspect ratio distributions for the shale gas samples for Sample 1 (Red), Sample 2 (Blue) and Sample 3 (Green).

Pore aspect ratio is a very important parameter in the characterisation of gas shales because it is not only related to the connectedness of the pores (Glover, 2009), which influences the electrical and fluid transport properties of the rock, it is also related to how effectively matrix-bound and kerogen-bound gas can diffuse into the shales pore spaces. High aspect ratios provide more grain-to-grain contact, thus decreasing the pore compressibility (Saleh and Castagna, 2004). Although not evaluated in routine or special core analysis, the aspect ratio distribution of a rock affects the connectedness and tortuosity of pore spaces, which control formation factors, cementation exponents, saturation exponents and ultimately permeability.

Figure 5 shows that there is a well-defined preferred aspect ratio that is shared by all samples (0.54, 0.42 and 0.56 for Sample 1, 2 and 3, respectively). However, Sample 2 and 3 contain pores with a much wider distribution of pore aspect ratios than Sample 1, indicating that while Sample 2 and Sample 3 contain some pores which are almost spherical as well as others which are very crack-like, together with all shapes in between, Sample 1 contains only pores in the middle range, which are never near-spherical nor very crack-like. In fact, Sample 1 has a well-defined maximum pore aspect ratio of 0.56 . The implication is clear; some gas shales contain more high aspect ratio pore spaces at a microscopic scale. These high aspect ratio pores are more likely to interlink and will be more likely to give these shales a larger natural permeability. Consequently, we ought to be searching for gas shales, which have high aspect ratios in order to take best advantage of any natural permeability that is present.

\subsection{Pore surface area to volume ratio}

The shape of each pore also affects its surface area to volume ratio, $\xi$. This ratio is important because large surface areas facilitate the diffusion of gas initially trapped in the matrix of the rock and in the kerogen into the pore spaces within the shale. This is a necessary step before hydraulic fracturing can open up access to these small pore spaces. A high surface area ensures that the diffusion process is more efficient, not only ensuring a good initial charge of gas in the micro-pores of the shale, but also allowing those pores to be recharged quickly once initial production has removed the initially accumulated gas. 
Solid Earth Discuss., https://doi.org/10.5194/se-2017-52

Manuscript under review for journal Solid Earth

Discussion started: 13 June 2017

Surface areas to volume ratios are best understood by assuming the ellipsoidal pores to be spheroids of either oblate or prolate types. Oblate spheroids have semi-axis sizes according to $a=b>c$, i.e., spheres squashed in the $c$-direction, and approximate to pennyshaped cracks or pores. Prolate spheroids have semi-axis sizes conforming to $a>b=c$, i.e., spheres stretched in the $a$-direction, and approximate to needles. The volume of both types of spheroid can be calculated using the formula

$$
V=\frac{4}{3} \pi a b c
$$

349

The surface area of the two types of spheroid differ slightly. They are

$$
\begin{aligned}
& S_{\text {oblate }}=2 \pi a^{2}\left(1+\frac{1-e^{2}}{e} \tanh ^{-1} e\right), \text { where } \quad e^{2}=1-\frac{c^{2}}{a^{2}} \quad \text { and } \\
& S_{\text {prolate }}=2 \pi a^{2}\left(1+\frac{c}{a e} \sin ^{-1} e\right), \text { where } \quad e^{2}=1-\frac{a^{2}}{c^{2}} .
\end{aligned}
$$

The surface area to volume ratio for each type are then

$$
\begin{aligned}
& \xi_{\text {oblate }}=\frac{3}{2 c}\left(1+\frac{1-e^{2}}{e} \tanh ^{-1} e\right), \text { and } \\
& \xi_{\text {prolate }}=\frac{3}{2 c}\left(1+\frac{c}{a e} \sin ^{-1} e\right) .
\end{aligned}
$$

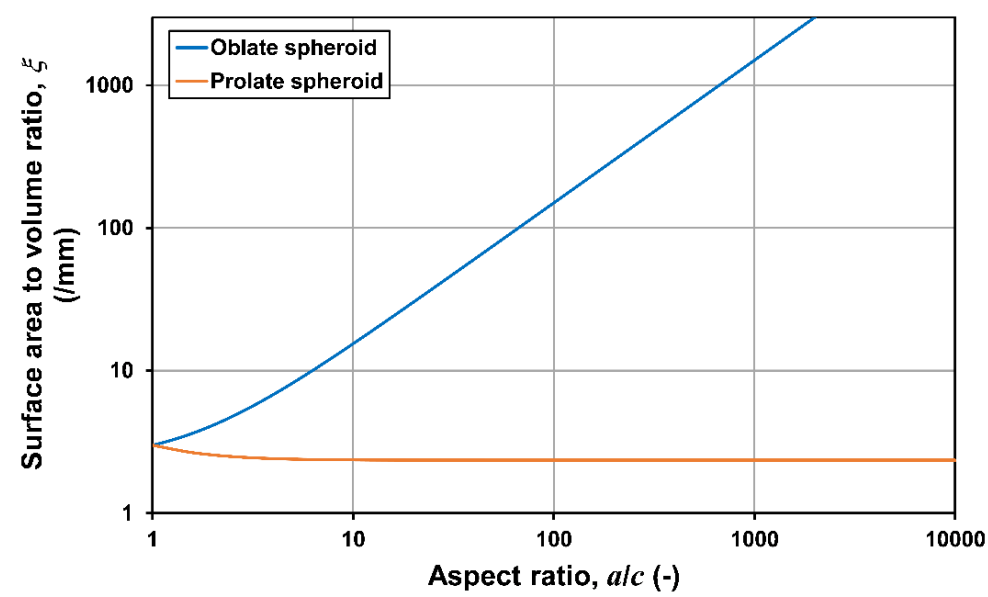

Figure 6. Surface area to volume ratio as a function of aspect ratio for oblate and prolate spheroids, approximating to penny-shaped and needle-shaped pores, respectively.

Figure 6 shows the relationship between the surface area to volume ratio $\xi$ of oblate, penny-shaped pores and prolate, needle shaped pores to their respective aspect ratios. It is clear that oblate pores provide a much greater surface area per volume than their respective prolate pores. The XRMT data shows that the pores in the three samples we have measured in this work are oblate with an aspect ratio of about 0.5, as shown in Figure 5. However, Figure 5 shows that aspect ratios as high as 0.84 and as low as 0.16 are also present. 
Solid Earth Discuss., https://doi.org/10.5194/se-2017-52

Manuscript under review for journal Solid Earth

Discussion started: 13 June 2017

(c) Author(s) 2017. CC BY 3.0 License.

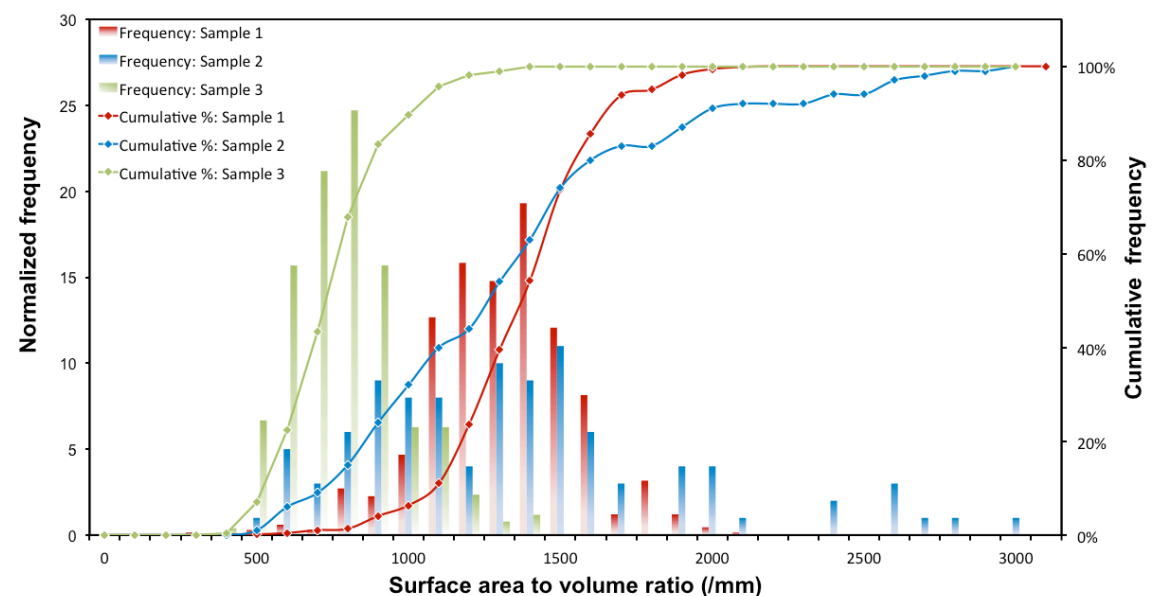

Figure 7. Surface area to volume ratio distributions of the pores. Sample 1 (Red), Sample 2 (Blue) and Sample 3 (Green)

Figure 7 shows the surface area to volume $(\xi)$ distributions for the three samples measured in this work. Samples 1 and 2 are similar with the $\xi$ ratio varying from about 500 $/ \mathrm{mm}$ to values higher than $2000 / \mathrm{mm}$ and similar modal values at about $1400 \pm 100 / \mathrm{mm}$ and $1500 \pm 100 / \mathrm{mm}$, respectively. Sample 3 is clearly different, varying from about $500 / \mathrm{mm}$ to values no higher than $1400 / \mathrm{mm}$ with a modal value at about $900 \pm 100 / \mathrm{mm}$.

The minimum surface area to volume ratios measured for all samples $(\xi=500 / \mathrm{mm})$ corresponds, according to the analysis in Figure 7 , to an $a / b$ aspect ratio of about 330 . In other words, the penny-shaped pore is 330 times wider than it is thick. Likewise, the maximum values of surface area to volume correspond to penny-shaped pores more than 1500 times wider than they are thick, with a modal behaviour for Sample 1 and Sample 2 showing $a / b$ aspect ratios of about 1000 and about 500 for Sample 3. The implication for gas production is clear; Sample 1 and Sample 2 have twice the surface area than Sample 3 for the diffusion of gas into the pores from the matrix, and these gas shales are likely to provide better long-term resource than that represented by Sample 3 even though, the higher porosity in Sample 3 will likely make it the better short-term prospect.

The surface area to volume ratio is also important in other respects. As indicated previously, high aspect ratio and high surface area to volume pores are much more likely to connect up with each other and therefore they are important in defining the natural permeability of the shale. In this regard, Sample 1 and Sample 2 would be expected to have a higher permeability than Sample 3. This is investigated later in this paper.

The shape of pores also is the importance in defining the geo-mechanical properties of the rock. Shales have a tendency to plastic behaviour so any tendency to weakness is likely to result in the closure of fractures and pores. High aspect ratio, high surface area to volume penny-shaped pores and cracks are much more prone to closure than those with low aspect ratios and low surface areas to volume (Glover et al., 2000; Curtis et al., 2010). Consequently, though high aspect ratios and high surface areas are beneficial for gas production they are also likely to be found in shales which are difficult to produce from because induced fractures will be more prone to closure in the long-term.

The previous analysis assumes that the pores behave like perfect smooth-surfaced spheroids. Of course this is not the case in reality as can be readily seen in Figure 3 . The 
Solid Earth Discuss., https://doi.org/10.5194/se-2017-52

Manuscript under review for journal Solid Earth

Discussion started: 13 June 2017

(c) Author(s) 2017. CC BY 3.0 License.

presence of rough surfaces on the pore walls increases the surface area to volume ratio above that which would be expected by the overall aspect ratio of the pore. It has been known for some years that not only pore size but also pore and fracture surfaces are fractal (Nolte et al., 1989; Bahr, 1997; Ogilvie et al., 2006), and fractal pores can in principle have a surface area to volume ratio that is infinite. Consequently, it should be considered that some samples might have much higher surface areas due to the roughness and of their surfaces, which do not increase the pore volumes but provide much larger pore surface areas. Approaches that take into consideration the fractal distribution of properties such as porosity and grain size are now being implemented in new reservoir modeling approaches and used to create fractal permeability models for shale gas flow (e.g., Geng et al., 2016; Li 420 et al., 2016).

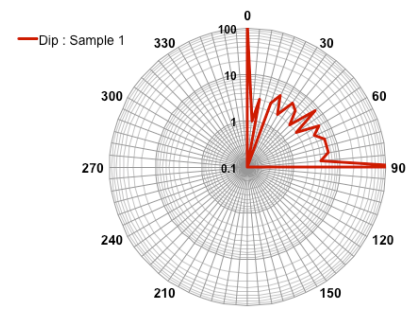
$\stackrel{180}{0}$

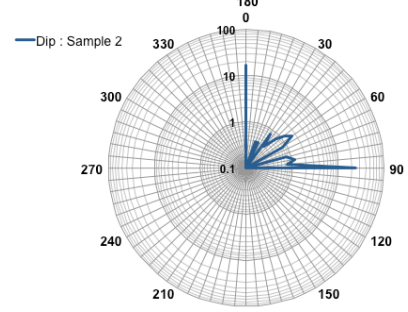

424

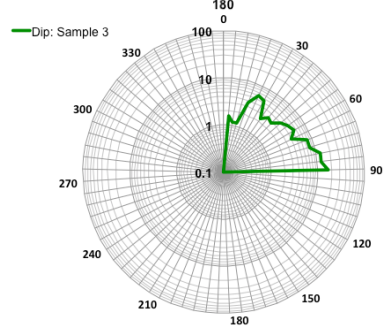

\subsection{Pore orientation}
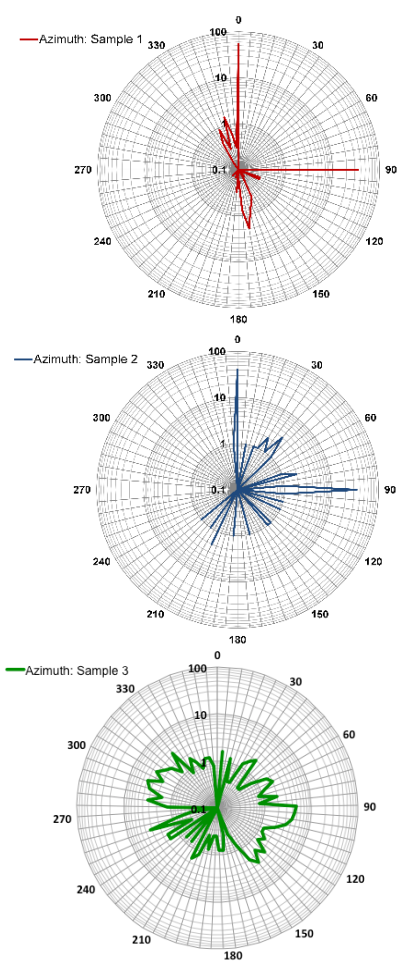

Figure 8. Rose diagrams of Dip and Azimuth of the long axis of pores for each of the samples studied. Sample 1 (Red), Sample 2 (Blue) and Sample 3 (Green).

The XRMT data can also be analysed to ascertain the orientation of the pores according to a polar co-ordinate system (Figure 8 shows the dip $\theta\left(0-90^{\circ}\right)$ and azimuth $\varphi\left(0-360^{\circ}\right)$ of the major axis of the pores for each sample as a rose diagram. It is immediately clear that the Sample 1 and Sample 2 are rather similar, showing marked preferential dips near $0^{\circ}$ and $90^{\circ}$, which is parallel to the tomographic stage and also to the macroscopic bedding observed in the samples. However, Sample 3 has preferential directions between $30^{\circ}$ and $80^{\circ}$. In addition Sample 1 and Sample 2 show marked preferential azimuthal directions which are orthogonal at $0^{\circ}$ and $90^{\circ}$ with additional secondary directions of which the two strongest are 
Solid Earth Discuss., https://doi.org/10.5194/se-2017-52

Manuscript under review for journal Solid Earth

Discussion started: 13 June 2017

(c) Author(s) 2017. CC BY 3.0 License. is well known that the mean effective pore radius can be calculated using the (Johnson et al. 1986) approach, where the effective pore diameter $\Lambda=2 V_{p} / S_{p}$, where $V_{p}$ is the pore volume and $S_{p}$ is the pore surface area. Consequently, $\Lambda=2 / \xi$. The $\Lambda$-value is a measure of the aperture for fluid flow which controls the permeability of the sample according to the relationship $k=\Lambda^{2} / 8 F$, where $F=\phi^{-m}$ is the formation factor of the rock (Glover, 2015). In this equation the value of $\Lambda$ describes the size of the opening between the rock grains allowing the passage of fluids, while the formation factor contains the information about how connected or tortuous those fluid flow pathways are (Glover, 2009; 2010). The formation factor was not measured directly in this work. However, since the cementation exponent $m$ for shales varies between about 2.34 and about 4.17 (Revil and Cathles, 1999), it is reasonable to assume a value of $m=3$. The formation factor can then be calculated using the measured porosity for each sample.

The permeability for each sample can then be calculated, and is found to be $92.3 \mathrm{nD}$, $5.49 \mathrm{nD}$ and $22.3 \mathrm{nD}$ for samples 1, 2 and 3, respectively (Table 1), which is in agreement with recent up-scaled permeability determinations for the Barnett shale (Peng et al., 2015). It is worth noting that Sample 3 does not have a larger permeability than Sample 1 despite having a larger porosity, which we ascribe to Sample 3 having a smaller surface area to volume ratio that has not been compensated for completely by the larger porosity of Sample 3.

The dimensions of the interconnected pores have a major role in our estimation of permeability and hence a viable theoretical method to find out effective pore radius or the size of opening between the rock grains is required. In order to validate the previous permeability calculations, ImageJ software has been used on SEM images of Sample 2 to measure the equivalent circular diameter of a crack, which is similar to the measured mean effective pore radius of same sample.

Figure 10 shows an SEM image of Sample 2 with a large crack. The crack has a length of approximately $19 \mu \mathrm{m}$, and is approximately 0.3 to $0.5 \mu \mathrm{m}$ wide. The equivalent diameter (Jennings et al., 1988) of that crack has been calculated with the following equation, and the value can then be compared with the effective pore radius of Sample 2 from Table 1.

$$
d_{e}=1.3(a b)^{0.625} /(a+b)^{0.25}
$$

where; $d_{e}$ is equivalent diameter $(\mu \mathrm{m}), a$ is the length of crack $(\mu \mathrm{m})$, and $b$ is the width of crack $(\mu \mathrm{m})$. For the crack shown in Figure 10 the equivalent diameter is roughly equal to 2.53 $\mu \mathrm{m}$ and the effective radius of it is equal to $1.26 \mu \mathrm{m}$, which corresponds extremely well to the effective pore radius of Sample 2 in Table $1(1.33 \mu \mathrm{m})$.

It is interesting to note that, for porosity and hence, permeability measurement, the equivalent diameter of cracks is not only depended on dimension of crack but also on flow properties. So the concept of equivalent diameter was only expressed for comparative purpose with effective pore radius. 
Solid Earth Discuss., https://doi.org/10.5194/se-2017-52

Manuscript under review for journal Solid Earth

Discussion started: 13 June 2017

(c) Author(s) 2017. CC BY 3.0 License.

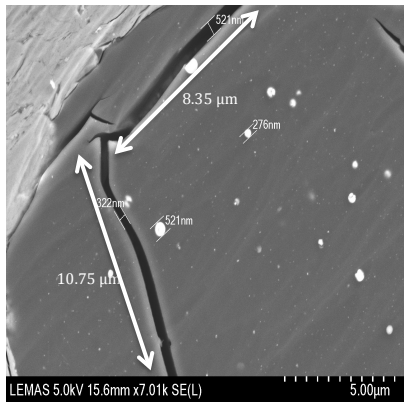

\section{Conclusions}

X-ray micro-tomography imaging (XRMT) has been used for qualitative and quantitative analysis of the pore structure of gas shale samples, attaining a spatial resolution of 0.9 to 1.2

$\mu \mathrm{m}$. Pore structure can be determined easily using the X-ray tomography technique thanks to the large density contrast between the solid matrix and the pore fluid.

The distribution of pore volume showed a great variability of pore scales for all three samples, and different porosities $(0.71 \%, 0.29 \%$ and $0.96 \%$ for Sample 1 , Sample 2 and Sample 3 respectively). These porosities were significantly lower than those obtained on the same samples by MICP measurement. The probable reason for this discrepancy is that the micro-tomography is not taking account of pores on a nanometric scale. Sample 1 was found to have a narrow range of pore aspect ratios, centred on 0.55 , with the pores being well aligned in a preferential direction, parallel to the bedding, while Sample 2 and 3 have a much wider range of aspect ratios, encompassing near-spherical pores and thin cracks, centred on 0.6 , i.e., close to the value for Sample 1. By contrast Sample 3 showed a less clear orientation of the pores. The surface area to volume ratio and permeability were calculated for all three samples.

Consideration of the porosity, pore size distributions, pore aspect ratio distributions, pore orientations and surface area to volume ratios as well as the calculated permeabilities shows Sample 1 to be the shale with the most shale gas potential.

Shale contains a wide range of pore sizes ranging from hundreds of microns down to a few nanometers (Alfred and Vernik, 2012). The lowest resolution achievable with the X-ray micro-tomographic instrument we used was about one micron. Hence, we expect that we have been analysing only the larger scale subset of the pores in the shale. Measurements are currently underway using an instrument with a nanometer scale resolution in order to ensure all sizes of pores are included in the measurement, and to examine whether the nanometer-scale pores are critical to our understanding of the pore microstructure of gas shale.

\section{Acknowledgments}

The authors would like to thank Rodrigo Guadarrama Lara for his great assistance during the use of the X-ray micro-tomography device at Leeds University and the University of Leeds for providing Paul Glover with an academic dowry. We would also like to thank Harri Wyn Williams for his help of sample preparation in Earth and Environment rock preparation laboratory.

\section{References}

1. Alfred, D., \& Vernik, L. (2013). A new petrophysical model for organic shales, Petrophysics, 54(3), 240-247. 
Solid Earth Discuss., https://doi.org/10.5194/se-2017-52

Manuscript under review for journal Solid Earth

Discussion started: 13 June 2017

(c) Author(s) 2017. CC BY 3.0 License.

2. Ambrose, R.J., Hartman, R.C., Diaz-Campos, M., Akkutlu, I.Y. and Sondergeld, C.H. (2012). Shale gas-in-place calculations. Part I. New pore-scale considerations: SPE Journal of Petroleum Engineers 17(1), 219-229.

3. Bahr, K. (1997). Electrical anisotropy and conductivity distribution functions of fractal random networks and of the crust: the scale effect of connectivity. Geophysical Journal International, 130(3), 649-660.

4. Bakke S., and Øren, P.E. (1997). 3-D Pore-Scale modelling of sandstones and flow simulations in the pore networks: SPE Journal of Petroleum Engineers, 2(02), 136-149.

5. Blunt M., Bijeljic, B., Dong, H., Gharbi, Q., Iglauer, S., Mostaghimi, P., Paluszny, A., and Pentland, C. (2013). Pore-scale imaging and modeling: Advances in Water Resources, 51, 197-216.

6. Buades, A., Coll, B., and Morel, J.M. (2011). Non-local means denoising: Image Processing On Line, 1, http://dx.doi.org/10.5201/ipol.2011.bcm_nlm

7. Chalmers, G.R., Bustin, R.M. and Power, I.M. (2012). Characterization of gas shale pore systems by porosimetry, pycnometry,surfacearea, andfield emission scanning electron microscopy/ transmission electron microscopy image analyses: Examples from the Barnett, Woodford, Haynesville, Marcellus, andDoig units. AAPG Bulletin, 96(6), 1099-1119.

8. Curtis M.E., Ambrose, R.J., Sondergeld, C.H. and Rai, C.S. (2010). Structural characterization of gas shales on the micro- and nano-scales: Paper SPE-137693-MS presented at the SPE Canadian Unconventional Resources and International Petroleum Conference.,_Calgary, Canada, 19-21 October 2010.

9. Edwards K., 2015. Unconventional reserves estimation with IHS Harmony, Principal Technical Analyst [online] Available at: http://blog.ihs.com/rpe-unconventional-reserves-estimationwith-ihs-harmony.

10. Geng, L., Li, G., Zitha, P., Tian, S. and Sheng, M. (2016). A fractal permeability model for shale gas flow through heterogeneous matrix systems. Journal of Natural Gas Science and Engineering, 35, 593-604

11. Gerke, K.M., Vasilyev, R.V., Korost, D.V., Karsanina, M.V., Balushkina, N.S., Kalmykov, G.A. and Mallants, D. (2013). Determining Physical Properties of Unconventional Reservoir Rocks: from Laboratory Methods to Pore-Scale Modeling. Society of Petroleum Engineers. SPE 167058, doi:10.2118/167058-MS

12. Glover P.W.J. (2009). What is the cementation exponent? A new interpretation: The Leading Edge, January 2009, 82-85.

13. Glover P.W.J. (2010). A generalised Archie's law for $n$ phases: Geophysics, 75(6), E247-E265, doi: 10.1190/1.3509781.

14. Glover, P.W.J., Gómez, J.B. and Meredith, P.G. (2000). Fracturing in saturated rocks undergoing triaxial deformation using complex electrical conductivity measurements: Experimental study. Earth and Planetary Science Letters, 183(1-2), 201-213

15. Glover P.W.J. (2015). Geophysical Properties of the Near Surface Earth: Electrical Properties, In: Gerald Schubert (editor-in-chief) Treatise on Geophysics, 2nd edition, Vol 11. Oxford: Elsevier, 89-137.

16. Glover, P.W.J., and Walker, E. (2009). A grain size to effective pore size transformation derived from an electro-kinetic theory, Geophysics, 74(1), E17-E29.

17. Glover, P.W.J., and Déry, N. (2010). Dependence of streaming potential on grain diameter and pore radius for quartz glass beads, Geophysics, 75(6), F225-241, doi: 10.1190/1.3509465

18. Henk G. M. (2009). Particle Size Measurements: Fundamentals, Practice, Quality. Springer. pp. 15

19. Iglauer S., Paluszny, A. and Blunt, M.J. (2013). Simultaneous oil recovery and residual gas storage: A pore-level analysis using in situ X-ray micro-tomography: Journal of Fuel 103, 905914.

20. Jennings, B., and Parslow, K. (1988). Particle Size Measurement: The Equivalent Spherical Diameter. Proceedings of the Royal Society of London. Series A, Mathematical and Physical Sciences, 419(1856), 137-149. Retrieved from http://www.jstor.org/stable/2398336

21. Johnson D.L., Koplik, J. and Schwartz, L.M. (1986). New pore-size parameter characterizing transport in porous media: Physical Review Letters, 57(20), 2564-2567, http://dx.doi.org/10.1103/PhysRevLett.57.2564 
Solid Earth Discuss., https://doi.org/10.5194/se-2017-52

Manuscript under review for journal Solid Earth

Discussion started: 13 June 2017

(c) Author(s) 2017. CC BY 3.0 License.

22. Li, B., Liu, R. and Jiang, Y. (2016). A multiple fractal model for estimating permeability of dualporosity media. Journal of Hydrology, 540, 659-669.

23. Li, G.G., Diaz, E., \& Nur, A. M. (2010). Rock Physical Properties Computed from Digital Core and Cuttings with Applications to Deep Gas Exploration and Development. Society of Petroleum Engineers. doi:10.2118/131601-MS

24. Loucks, R.G., Reed, R.M., Ruppel, S.C. and Jarvie, D.M. (2009). Morphology, genesis, and distribution of nanometer-scale pores in siliceous mudstones of the mississippian barnett shale. Journal of Sedimentary Research, 79(12), 848-861.

25. Markowicz, A.A. (1993). X-ray physics. Handbook of X-ray Spectrometry, 14, 1-28.

26. Mayo, S., Josh, M., Nesterets, Y., Esteban, L., Pervukhina, M., Clennell, M.B., Maksimenko, A. and Hall, C. (2015). Quantitative micro-porosity characterization using synchrotron micro-CT and xenon K-edge subtraction in sandstones, carbonates, shales and coal. Fuel, 154, 167-173.

27. Mersereau R.M. and Dudgeon D.E. (1975). Two-dimensional digital filtering. Proceedings of the IEEE, 63, 610-623.

28. Miller R. G., and Steven R. S. (2014). The Future of Oil Supply. Mathematical, physical, and engineering sciences.

29. Nolte, D.D., Pyrak-Nolte, L.J. and Cook, N.G.W. (1989). The fractal geometry of flow paths in natural fractures in rock and the approach to percolation. Pure and Applied Geophysics PAGEOPH, 131(1-2), 111-138.

30. Ogilvie, S.R., Orribo, J.M., and Glover, P.W.J. (2001). The influence of deformation bands upon fluid flow using profile permeametry and positron emission tomography: Geophysics Research Letters, 28(1), 61-64.

31. Ogilvie, S.R., Isakov, E. and Glover, P.W.J. (2006). Fluid flow through rough fractures in rocks. II: A new matching model for rough rock fractures. Earth and Planetary Science Letters, 241(3-4), 454-465.

32. Panahi H., Kobchenko, M., Renard, F., Mazzini, A., Scheibert, J., Dysthe, D., Jamtveit, B., Malthe-Sorenssen, A. and Meakin, P. (2014). A 4D synchrotron X-ray tomography study of the formation of hydrocarbon migration pathways in heated organic-rich shale, SPE Journal of Petroleum Engineers, 18(02), 366-377.

33. Peng S.H., Hu, O., Dultz, S. and Zhang, M. (2012). Using X-ray computed tomography in pore structure characterization for a Berea sandstone: Resolution effect: Journal of Hydrology, 472, 254-261.

34. Peng, S., Yang, J., Xiao, X., Loucks, B., Ruppel, S.C. and Zhang, T. (2015). An Integrated Method for Upscaling Pore-Network Characterization and Permeability Estimation: Example from the Mississippian Barnett Shale. Transport in Porous Media, 109 (2), 359-376.

35. Passey, Q. R., Bohacs, K., Esch, W. L., Klimentidis, R., \& Sinha, S. (2010). From Oil-Prone Source Rock to Gas-Producing Shale Reservoir - Geologic and Petrophysical Characterization of Unconventional Shale Gas Reservoirs. Society of Petroleum Engineers. doi:10.2118/131350-MS

36. Reipe L., and Suhaimi, M.H.B. (2011). Application of high resolution micro-CT imaging and pore network modeling (PNM) for the petrophysical characterisation of tight gas reservoir A case history from a deep clastic tight gas reservoir in Oman: Paper SPE-142472-MS presented at the SPE Middle East Unconventional Gas Conference and Exhibition. Muscat, Oman, 31st January - 2nd February, 2011.

37. Revil, A., and Cathles, L.M. (1999). Permeability of shaly sands: Water Resources Research, 35(3), 651-662.

38. Richardson, N. and Gottlieb, M. (2013). The state of shale gas regulation. Resource for the future, 16, 31-39.

39. Saleh A., and Castagna, J.P. (2004). Revisiting the Wyllie time average equation in the case of near-spherical pores: Journal of The Society of Exploration Geophysicists, 69 (1), 45-55.

40. Schieber, J. (2010). Common Themes in the Formation and Preservation of Intrinsic Porosity in Shales and Mudstones - Illustrated with Examples Across the Phanerozoic. Society of Petroleum Engineers. doi:10.2118/132370-MS

41. Sondergeld C.H., Ambrose, R.J., Rai, C.S. and Moncrieff, J. (2010). Micro-structural studies of gas shales: Paper SPE-131771-MS presented at the SPE Unconventional Gas Conference, Pittsburgh, Pennsylvania, USA, 23-25 February 2010. 
Solid Earth Discuss., https://doi.org/10.5194/se-2017-52

Manuscript under review for journal Solid Earth

Discussion started: 13 June 2017

(c) Author(s) 2017. CC BY 3.0 License.

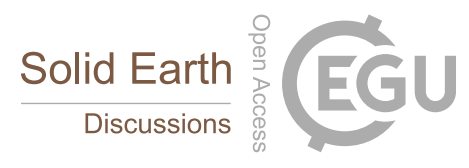

(c) (1)

636

637

638

639

640

641
42. Tissot B.P. and. Welte, D.H. (1978). Petroleum Formation and Occurrence. A new Approach to Oil and Gas Exploration. XVIII. Berlin-Heidelberg-New York 1978.

43. Vernik, L. and Liu, X. (1997). Velocity anisotropy in shales: A petrophysical study. Geophysics, 62, 521-532.

44. Ward, J. (2010). Kerogen density in the Marcellus shale, Society of Petroleum Engineers, SPE131767-MS, doi: 10.2118/131767-MS 